\title{
DETEKSI PLAGIARISME TINGKAT KEMIRIPAN JUDUL SKRIPSI PADA FAKULTAS TEKNOLOGI INFORMASI MENGGUNAKAN ALGORITMA WINNOWING
}

\author{
Nur Alamsyah ${ }^{1)}$, Muhammad Rasyidan ${ }^{2)}$ \\ ${ }^{\text {I}}$ Fakultas Teknologi Informasi, Universitas Islam Kalimantan Muhammad Arsyad Al Banjari Banjarmasin \\ Email: uniskalam@gmail.com \\ ${ }^{2}$ Fakultas Teknologi Informasi, Universitas Islam Kalimantan Muhammad Arsyad Al Banjari Banjarmasin \\ Email: mr.syidan@gmail.com
}

\begin{abstract}
ABSTRAK
Untuk menentukan kemiripan teks judul skripsi yang di ajukan dengan judul-judul skripsi yang telah ada sebelumnya maka diperlukan penerapan suatu algoritma untuk menentukan kemiripan teks, salah satunya algoritma untuk menentukan kemiripan teks ialah algoritma Winnowing.

Algoritma Winnowing adalah sebuah cara yang digunakan untuk mendeteksi kesamaan kata/kalimat (common subsequence) dalam dua atau lebih teks yang dibandingkan. Dua teks diketahui memiliki kesamaan kata/kalimat apabila di dalam dokumen tersebut dijumpai fingerprint, fingerprint inilah yang akan dijadikan dasar pembanding antara teks, algoritma ini akan mencari fingerprint (kesamaan di dalam dua teks) dengan cara mengubah n-gram dari sebuah teks ke dalam bentuk nilai angka yang disebut dengan nilai hash, teknik untuk mencari nilai tersebut adalah Hashing.

Dengan sistem ini, Ketua Program Studi atau Koordinator Tugas Akhir nantinya hanya memasukkan judul yang akan diajukan mahasiswa, kemudian sistem akan mengecek secara otomatis dan menampilkan hasilnya. Hasil tersebut bisa dijadikan sebagai pertimbangan dalam pengambilan keputusan dan dapat menentukan apakah diterima atau ditolak judul skripsi tersebut.
\end{abstract}

Kata kunci : Algoritma Winnowing, fingerprint, n-gram, Hashing

\section{PENDAHULUAN}

Seiring berjalannya waktu telah banyak judul-judul skripsi yang telah diterima dan tersimpan di akademis. Dalam pengajuan judul tidak sedikit mahasiswa yang berulang kali mengajukan judul skripsi, hal ini dikarenakan mahasiswa tersebut tidak mengetahui judul yang diajukan telah ada sebelumnya karena penentuan diterima atau ditolaknya judul-judul yang diajukan oleh mahasiswa masih dilakukan secara manual yaitu dengan dengan mengecek satu persatu berdasarkan daftar judul-judul skripsi angkatan yang telah lulus yang tersimpan di file Microsoft excel.

Judul skripsi yang sama, tidak menutup kemungkinan isi dari skripsi tersebut juga sama namun tidak menutup kemungkinan juga isi skripsi berbeda walaupun judul skripsi sama sehingga mahasiswa bingung dalam menentukan judul skripsinya. Dalam menentukan diterima atau tidaknya sebuah judul skripsi yang sekarang ini dilakukan adalah dengan mengecek atau membandingkan judul tersebut dengan daftar judul-judul yang telah ada, tentu saja hal ini akan membutuhkan waktu yang cukup lama belum lagi jika pengaju judul skripsi berjumlah banyak, tidak menutup kemungkinan ada judul yang terulang atau sama dengan judul-judul yang tersimpan di akademis bahkan waktu yang dibutuhkan juga akan semakin lama.

Di samping itu, pengelolaan daftar judul-judul yang telah ada juga masih manual sehingga tidak menutup kemungkinan data akan hilang dan sulit dalam 
mendistribusikan informasi tersebut kepada mahasiswa. Oleh karena itu, diperlukan suatu sistem yang mampu mendeteksi persentase kemiripan teks judul secara cepat dan tepat dan mampu menyediakan informasi tersebut kepada seluruh mahasiswa.

Untuk menentukan kemiripan teks judul skripsi yang di ajukan dengan juduljudul skripsi yang telah ada sebelumnya maka diperlukan penerapan suatu algoritma untuk menentukan kemiripan teks, salah satunya algoritma untuk menentukan kemiripan teks ialah algoritma Winnowing.

Algoritma Winnowing adalah sebuah cara yang digunakan untuk mendeteksi kesamaan kata/kalimat (common subsequence) dalam dua atau lebih teks yang dibandingkan. Dua teks diketahui memiliki kesamaan kata/kalimat apabila di dalam dokumen tersebut dijumpai fingerprint, fingerprint inilah yang akan dijadikan dasar pembanding antara teks, algoritma ini akan mencari fingerprint (kesamaan di dalam dua teks) dengan cara mengubah n-gram dari sebuah teks ke dalam bentuk nilai angka yang disebut dengan nilai hash, teknik untuk mencari nilai tersebut adalah Hashing.

Dengan sistem ini, Koordinator Tugas Akhir atau Ketua Program Studi nantinya hanya memasukkan judul yang akan diajukan ke formulir yang telah disediakan, kemudian sistem akan mengecek secara otomatis dan menampilkan hasilnya. Hasil tersebut bisa dijadikan sebagai pertimbangan dalam menentukan apakah diterima atau ditolak judul tersebut.

\section{METODE PENELITIAN}

Metode Pendeteksi Plagiarisme di bagi menjadi tiga bagian yaitu metode perbandingan teks lengkap, metode dokumen fingerprinting, dan metode kesamaan kata kunci. Klasifikasi metode pendeteksi plagiarisme dapat digambarkan sebagai
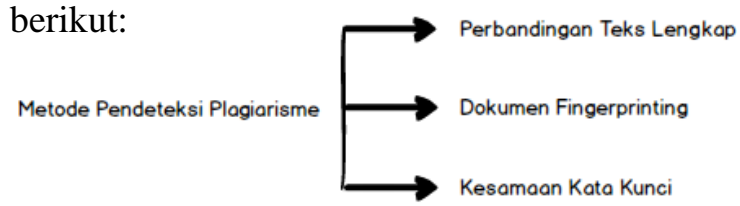

Gambar 1. Klasifikasi Metode Pendeteksi Plagiarisme
Ketiga metode diatas dapat diuraikan sebagai berikut (Stein, 2006) :

\section{Perbandingan Teks Lengkap}

Metode ini di terapkan dengan membandingkan semua isi dokumen. Dapat diterapkan untuk dokumen yang besar. Pendekatan ini membutuhkan waktu yang lama tetapi cukup efektif, karena kumpulan dokumen yang diperbandingkan adalah dokumen yang di simpan pada penyimpanan lokal. Metode perbandingan teks lengkap tidak dapat diterapkan untuk kumpulan dokumen yang tidak terdapat pada dokumen lokal.

Algoritma yang digunakan pada metode ini adalah algoritma brute force, algoritma edit distance, algoritma boyer moore dan algoritma lavenshtein distance

\section{Dokumen Fingerprinting}

Dokumen fingerprinting merupakan metode yang digunakan untuk mendeteksi keakuratan salinan antar dokumen, baik semua teks yang terdapat di dalam dokumen atau hanya sebagian teks saja. Prinsip kerja dari metode dokumen fingerprinting ini adalah dengan menggunakan teknik hashing. Teknik hashing adalah sebuah fungsi yang mengkonversi setiap string menjadi bilangan.

\section{Kesamaan Kata Kunci.}

Prinsip dari metode ini adalah mengekstrak kata kunci dari dokumen dan kemudian di bandingkan dengan kata kunci pada dokumen yang lain. Pendekatan yang digunakan pada metode ini adalah teknik dot.

\section{HASIL DAN PEMBAHASAN}

\section{Hasil Analisis Algoritma Winnowing}

Penelitian ini menggunakan metode eksperimen, dengan tahapan penelitian sebagai berikut:

\section{Pengolahan Data}

Data yang digunakan berupa dokumen teks yang berasal dari judul-judul skripsi mahasiswa yang telah lulus mulai angkatan Tahun 2011 sd angkatan tahun 2013 dengan total 1092 Judul skripsi, kemudian data yang tersimpan di Microsoft excel nantinya akan 
diiputkan ke form input data aplikasi deteksi plagiarisme, berikut contoh data dalam bentuk excel,

\section{Analisis Deteksi Kemiripan dengan Algoritma Winnowing}

Proses deteksi kemiripan judul dapat dilakukan dengan menerapkan berbagai metode untuk menghasilkan presentasi kemiripan. Tujuan utama dari deteksi kemiripan judul adalah untuk menentukan presentase kemiripan judul satu dengan judul lainya.

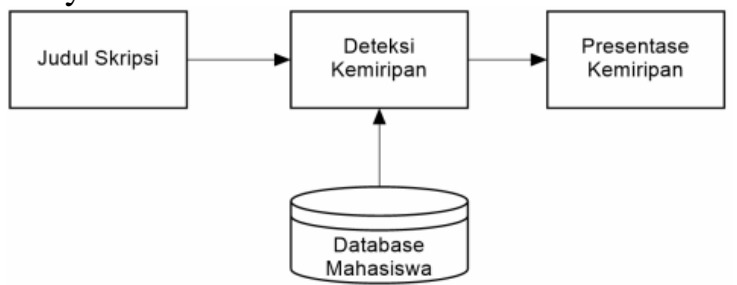

Gambar 2. Skema deteksi kemiripan judul skripsi

Deteksi kemiripan judul skripsi dapat dideteksi dengan salah satu algoritma yaitu dengan algoritma winnowing dimana hasil presentase kemirpan judul ditampilkan. Proses deteksi kemiripan dilakukan dengan menampilkan presentase dengan mengunakan Persamaan Jaccard Coeficient pada hasil Fingerprint.

Adapun langkah-langkah deteksi kemiripan judul skripsi adalah sebagai berikut:

1. Masukan judul skripsi yang akan dilihat tingkat presentase nya dengan judul skripsi yang sudah ada sebelumnya.

2. Memasukan nilai n-gram, untuk memebentuk rangkaian gram pada judul yang dimasukan dan judul yang dibandingkan.

3. Masukan nilai Window, untuk menentukan pembentukan window dari nilai Hash.

4. Proses deteksi kemiripan judul skripsi dengan algoritma winnowing yang mana tujuanya dari proses deteksi kemiripan judul tersebut ada untuk menampilkan tingkat presentase dengan judul-judul yang sudah ada sebelumnya. Berdasarkan analisa di atas, dapat disimpulkan bahwa proses deteksi kemirpan judul skripsi berdasarkan algoritma winnowing menghasilkan presentase kemiripan dengan kumpulan judul skripsi yang sudah ada, karena semakin tinggi presentase kemiripan maka akan semakin mirip dengan judul yang dibandingkan.

\section{Implementasi Algoritma Winnowing}

Tahapan-tahapan untuk mengimplementasikan Algoritma Winnowing untuk mendeteksi presentase plagiarisme pada judul skripsi adalah sebagai berikut;

1. Ambil 2 judul skripsi yang akan dibandingkan.

Teks Judul 1:

\begin{tabular}{c|}
\hline "APLIKASI LAYANAN \\
KEPENDUDUKAN ELEKTRONIK PADA \\
DINAS KEPENDUDUKAN DAN \\
PENCATATAN SIPIL KOTA \\
BANJARMASIN" \\
\hline
\end{tabular}

Teks Judul 2:

\section{"SISTEM INFORMASI MANAJEMEN \\ LAYANAN KEPENDUDUKAN PADA DISCAPIL KOTA BANJARMASIN"}

\section{Pembuangan Karakter yang Tidak Relevan}

Hapus semua huruf yang bukan A-Z, a-Z, 0-9. Kemudian ubah menjadi huruf kecil semua.

Teks Judul 1 akan terbentuk menjadi seperti berikut:
aplikasilayanankependudukanelektronikpada dinaskependudukandanpencatatan sipilkotabanjarmasin

dan Teks Judul 2 akan terbentuk menjadi seperti berikut:

sisteminformasimanajemenlayanankependud ukanpadadiscapilkotabanjarmasin

3. Pembentukan Rangkaian n-gram

Buat $n$-gram untuk masing-masing judul kalimat. Jumlah data pengelompokan $n$-gram ini bisa dimulai dari 2, 3, 5, 7 dan seterusnya misal $n$ gram $=3$.

Pada teks Judul 1 akan terbentuk 87 rangkaian ngram yaitu:

Pada teks Judul 1 akan terbentuk 87 rangkaian ngram yaitu: 
apl pli lik ika kas asi sil ila lay aya yan ana nan ank nke kep epe pen end ndu dud udu duk uka kan ane nel ele lek ekt ktr tro ron oni nik ikp kpa pad ada dad adi din ina nas ask ske kep epe pen end ndu dud udu duk uka kan and nda dan anp npe pen enc nca cat ata tat ata tan ans nsi sip ipi pil ilk lko kot ota tab aba ban anj nja jar arm rma mas asi sin

Sedangkan pada teks Judul 2 terbentuk 66 rangkaian n-gram yaitu:

sis ist ste tem emi min inf nfo for orm rma mas asi sim ima man ana naj aje jem eme men enl nla lay aya yan ana nan ank nke kep epe pen end ndu dud udu duk uka kan anp npa pad ada dad adi dis isc sca cap api pil ilk lko kot ota tab aba ban anj nja jar arm rma mas asi sin

\section{Perhitungan Fungsi Hash untuk Setiap n-gram}

Buat Rolling Hash untuk masing-masing N-Gram, Perhitungan nilai hash pada rangkaian n-gram pada teks judul 1 bagian pertama "apl" dengan nilai basis (b) $=2$, panjang rangkaian ngram $(\mathrm{n})=3$ $\mathbf{H}_{(a p l)}=\operatorname{asci}_{(\mathrm{a})} * 2^{3}+\operatorname{asci}_{(\mathrm{p})} * 2^{2}+\operatorname{asci}_{(\mathrm{l})} *$ $2^{1}$

$$
=97 * 8+112 * 4+108 * 2
$$$$
=1440
$$

\section{Pembentukan Window dari Nilai Hash}

Kelompokkan (windowing) untuk masing-masing hasil hash, langkahnya mirip seperti n-gram. Pembentukan window dari hasil perhitungan nilai hash dengan ukuran lebar window $(\mathrm{w})=3$ pada teks judul 1 yaitu:

\begin{tabular}{|c|c|}
\hline 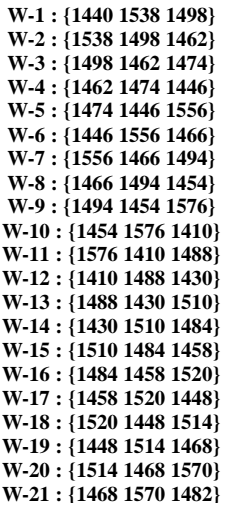 & 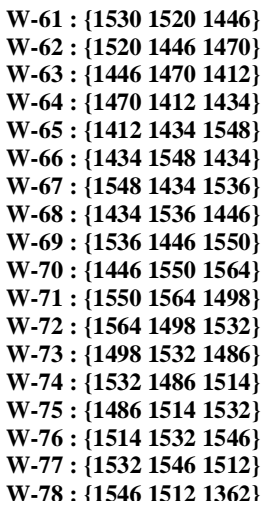 \\
\hline
\end{tabular}

Kemudian pada teks judul 2 hasilnya yaitu;

\begin{tabular}{|c|c|}
\hline$W-1:\left\{\begin{array}{llll}1570 & 1532 & 1586\end{array}\right\}$ & $W-49:\left\{\begin{array}{llll}1498 & 1510 & 1404\end{array}\right\}$ \\
\hline $\mathrm{W}-2:\{153215861550\}$ & $\mathrm{W}-50:\{151014041434\}$ \\
\hline$W-3:\left\{\begin{array}{llll}1586 & 1550 & 1454\end{array}\right\}$ & $\mathrm{W}-51:\{140414341532\}$ \\
\hline W-4 : $\{155014541512\}$ & $\mathrm{W}-52:\{143415321486\}$ \\
\hline W-5 : $\{145415121484\}$ & $\mathrm{W}-53:\{153214861514\}$ \\
\hline W-6 : $\{151214841510\}$ & $\mathrm{W}-54:\{148615141532\}$ \\
\hline $\mathrm{W}-7:\{148415101488\}$ & $\mathrm{W}-55:\{151415321546\}$ \\
\hline $\mathrm{W}-8:\{151014881562\}$ & $\mathrm{W}-56:\{153215461512\}$ \\
\hline $\mathrm{W}-9:\{148815621542\}$ & $\mathrm{W}-57:\{154615121362\}$ \\
\hline$W-10:\left\{\begin{array}{lll}1562 & 1542 & 1490\end{array}\right\}$ & $\mathrm{W}-58:\{151213621392\}$ \\
\hline W-11 : $\left\{\begin{array}{llll}1542 & 1490 & 1446\end{array}\right\}$ & $\mathrm{W}-59:\{136213921428\}$ \\
\hline W-12 : $\{149014461558\}$ & W-60 : $\{139214281498\}$ \\
\hline W-13: $\left\{\begin{array}{llll}1446 & 1588 & 1470\end{array}\right\}$ & W-61: $\{142814981464\}$ \\
\hline W-14: $\left\{\begin{array}{llll}1558 & 1470 & 1480\end{array}\right\}$ & W-62: $\{149814641450\}$ \\
\hline W-15: $\{147014801410\}$ & $\mathrm{W}-63:\left\{\begin{array}{lll}1464 & 1450 & 1542\}\end{array}\right.$ \\
\hline W-16: $\left\{\begin{array}{llll}1480 & 1410 & 1480\end{array}\right\}$ & W-64: $\{145015421490\}$ \\
\hline W-17: $\left\{\begin{array}{llll}1410 & 1480 & 1402\end{array}\right\}$ & W-65: $\{154214901446\}$ \\
\hline W-18 : $\left\{\begin{array}{llll}1480 & 1402 & 1470\end{array}\right\}$ & $\mathrm{W}-66:\{149014461560\}$ \\
\hline
\end{tabular}

6. Pemilihan Fingerprint dari Setiap Window

Ambil angka terkecil dari masing-masing window. Untuk selanjutnya angka terkecil ini diistilahkan Fingerprints. Pemilihan nilai fingerprint dari hasil pembentukan window pada tahap sebelumnya adalah ;

nilai fingerprint pada teks judul 1 adalah $\mathbf{7 8}$ window

nilai fingerprint pada teks judul 2 adalah $\mathbf{6 6}$ window

Fingerprints dari kelompok (window) kalimat teks judul 1 dengan fingerprints (window) kalimat teks judul 2 inilah yang nanti akan dihitung tingkat koefisien plagiarisme-nya

\section{Persamaan Jaccard Coeficient}

Perhitungan kesamaan dengan menggunakan persamaan jaccard coefficient yaitu;

Similarity $($ kemiripan $)=65 / 88 * 100 \%=$ $73.86 \%$

Jumlah Fingerprints pada teks judul $1=87$

Jumlah Fingerprints teks judul $2=66$

Union (Gabungan) Fingerprints 1 dan $2=153$

Intersection (fingerprints yang sama) $=65$

$($ Union - Intersection $)=88$

Prosentase Plagiarisme

Koefisien Jaccard $=$ (Intersection / (UnionIntersection) $* 100(65 / 88) * 100=\mathbf{7 3 . 8 6} \%$

Jadi dapat disimpulkan dari kedua judul diatas memiliki tingkat plagiarisme sebesar 73.86 \% Pengujian Metode Winnowing

Untuk Fakultas Teknologi Informasi menggunakan ambang batas seperti berikut:

\section{Ambang Batas (Threshold) Plagiarisme}

Plagiarisme Ringan : $<=35 \%$

Plagiarisme Sedang: $36 \%-70 \%$

Plagiarisme Berat $\quad>70 \%$

Jurnal Ilmiah "Technologia" 
Apabila Plagiarisme ringan maka judul DITERIMA sedangkan untuk plagiarism sedang dan berat maka judul DITOLAK.

\section{KESIMPULAN DAN SARAN}

Proses pengujian dilakukan mulai dari pegujian jumlah gram, jumlah window dan basis bilangan prima. Dapat dilihat pada tabel dibawah ini;

Tabel hasil pengujian deteksi tingkat plagiarisme pada judul skripsi

\begin{tabular}{|c|c|c|c|c|}
\hline No & $\begin{array}{c}\text { n-gram } \\
(\mathbf{n})\end{array}$ & Window(w) & $\begin{array}{c}\text { Nilai } \\
\text { basis }\end{array}$ & Presentase \% \\
\hline 1 & 3 & 3 & 2 & $\mathbf{7 3 . 8 6} \%$ \\
\hline 2 & 5 & 3 & 2 & $\mathbf{3 6 . 7} \%$ \\
\hline 3 & 7 & 3 & 2 & $\mathbf{2 9 . 4 6} \%$ \\
\hline 4 & 3 & 5 & 2 & $\mathbf{7 3 . 2 6} \%$ \\
\hline 5 & 5 & 5 & 2 & $\mathbf{3 6 . 7 9} \%$ \\
\hline 6 & 7 & 5 & 2 & $\mathbf{2 9 . 3 6} \%$ \\
\hline 7 & 3 & 7 & 2 & $\mathbf{5 5 . 9 1} \%$ \\
\hline 8 & 5 & 7 & 2 & $\mathbf{3 0 . 5 6} \%$ \\
\hline 9 & 7 & 7 & 2 & $\mathbf{2 3 . 4 2} \%$ \\
\hline 10 & 3 & 9 & 2 & $\mathbf{5 0 \%}$ \\
\hline 11 & 5 & 9 & 2 & $\mathbf{3 1 . 7 3} \%$ \\
\hline 12 & 7 & 9 & 2 & $\mathbf{1 9 . 8 2} \%$ \\
\hline
\end{tabular}

Berdasarkan dari tabel hasil Pengujian diatas dalam menentukan tingkat plagiarisme dengan menggunakan n-gram, window, bilangan prima menghasilkan $\mathbf{7 3 . 8 6} \%$ tingkat plagiarisme tinggi artinya mendekati plagiarisme dengan $n$-gram $=3$, window $=3$ dan bilangan prima $=2$ sedangkan dengan menggunakan $n$-gram $=3$, window $=3$ dan bilangan prima $=2$ menghasilkan 19.82 \% artinya hanya mempunyai tingkat plagiarisme ringan

\section{REFERENSI}

Astuti, W. (Agustus 2017). Analisis String Matching Pada Judul Skripsi dengan Algoritma Knuth-Morris Pratt(KMP). ILKOM Jurnal Ilmiah Volume 9 Nomor 2 ISSN Cetak 2087-1716 ISSN Online 2548-7779, 168 - 172.

Astutik, S., Cahyani, A. D., \& Sophan, M. K. (November 2014). Sistem Penilaian Esai Otomatis pada E-Learning dengan Algoritma Winnowing. Jurnal Informatika, Vol 12, No.2 ISSN 14110105, 47-52.

Christian. (2013). Perancangan Sistem Deteksi Plagiarisme Dokumen Teks
Menggunakan Algoritma Damerau Levenshtein Distance. Jurnal Mahasiswa PTIIK UB Vol 1.

Nurdin, \& Amin, M. (September 2017). Sistem Pendeteksian Kemiripan Judul Skripsi Menggunakan Algoritma Winnowing. Jurnal Nasional Informatika dan Teknologi Jaringan (InfoTekJar) Vol 2, No 1 e-ISSN : 2540-7600, p-ISSN : 2540-7597.

Ridho, M. (2013). Rancang Bangun Aplikasi Pendeteksi Penjiplakan Dokumen Menggunakan Algoritma Biword Winnowing . Pekanbaru Riau: UNIVERSITAS ISLAM NEGERI SULTSN SYARIF KASIM .

Setiawan, A. (Januari 2017). Implementasi Algoritma Winnowing Untuk Deteksi Kemiripan Judul Skripsi Studi Kasus STIMIK Budidarma. Majalah Ilmiah INTI Volume: XII, Nomor : 1 ISSN : 2339-210X. 